\title{
Rapid Preparation of a Composite Insulating Block Comprising Waste Expanded Polystyrene (EPS) Foam and Rice Straw
}

\begin{abstract}
Yuting Dou, Anhong Bao,* Duhong Sun, and Zenan Niu
Due to the world's decreasing energy supply, reducing the energy consumption of building envelopes has become an urgent issue with economic benefits. Rice straw is a generally available agricultural residue. The purpose of this study was to estimate the effects of rapid pretreatment methods and slaked lime on the molding of rice straw insulation blocks and to evaluate the effectiveness of integrating expanded polystyrene (EPS) particle waste with rice straw as building materials to reduce the energy loss in buildings. The pretreatment time was shortened from $6 \mathrm{~h}$ to $3 \mathrm{~h}$ by mechanical stirring combined with lye soaking. The molding of the insulation block could be improved by the hardening of slaked lime through contrast experiments and electron microscope scanning. Moreover, the influences of the mass ratio of slaked lime to rice straw (RSR) and the dosage of the EPS particles ( $\omega_{\mathrm{EPS}}$ ) on the dry apparent density and the thermal conductivity of the insulation blocks were studied. The results showed that the slaked lime would increase the dry apparent density and weight of the insulation block, but the EPS can effectively reduce this negative effect and keep the thermal conductivity of the insulation block below $0.049 \mathrm{~W} \cdot \mathrm{m}^{-1} \cdot \mathrm{K}^{-1}$. Ultimately, the rapid pretreatment technology was determined to include lye soaking for $3 \mathrm{~h}$ and mechanical stirring for $5 \mathrm{~min}$. The material matching ratio scheme was determined to have a $\omega_{\text {EPS }}$ value of less than $3 \%$ and an RSR value equal to $1 / 7.5$.
\end{abstract}

DOI: 10.15376/biores.17.1.699-713

Keywords: Rice straw; Hydrated lime; Expanded polystyrene foam waste; Rice straw insulation block; Preparation technology

Contact information: College of Engineering and Technology, Southwest University, Chongqing 400715 China; *Corresponding author: baoanhong@163.com

\section{INTRODUCTION}

Currently, the world is confronted with fundamental problems regarding a deficiency of energy resources, environmental pollution, ozone depletion, and climate change (Carlini et al. 2014; Sun and Yu 2021). Reducing energy consumption is imperative to confront these issues. Buildings account for the maximal share of energy use, and they are responsible for 40 percent of global energy consumption (Huo et al. 2018). Studies focusing on new construction materials using local raw materials need to be carried out, contributing to a reduction in energy consumption (Florea and Manea 2019). The thermal insulation of building envelopes is a technique that can avoid high energy consumption due to heating, cooling, and air conditioning systems. In Asia, especially in south China, rice is a staple food grain crop that produces rice straw as a waste byproduct (around 731 MT globally each year) (Saini et al. 2015). Given the low density, porous structure, abundant resources, and outstanding heat insulation characteristics of rice straw, it has been used as 
building envelope insulation material for a long time. This combination not only utilizes the agricultural waste adequately but also facilitates the construction of buildings with a significantly lower environmental impact. In addition, it has certain economic benefits, for example, reducing costs of construction materials and reducing costs for cooling during summer and heating during winter (Hussein et al. 2019).

Rice straw has been used in building envelopes, such as straw bales, straw fiber bio-composite board, and straw cement-based building material, among others. Straw bales can be used to construct a comfortable and eco-friendly building environment, which benefits from its certain bearing capacity, strong insulation of heat and sound, low energy consumption, and absence of negative environmental impacts (Bhattacharyya et al. 2020). From an operational point of view, the essential characteristics of straw building systems can be summarized by grouping them into three broad categories: load bearing, in-fill, and mixed system (Mutani et al. 2020). However, the thermal conductivity of straw bale is closely related to hygrothermal conditions in building components. If subjected to excessive moisture level, there is high probability of mold growth and straw degradation, and its thermal insulation performance decreases (Koh and Kraniotis 2020). Straw fiber bio-composite boards include medium-density fiberboard (MDF), particleboard, and plastic bonded board (Aladejana et al. 2020). The straw fiber bio-composite board stands a chance of lowering the requirements for both air conditioning and heating, thereby economizing the energy in buildings (Marques et al. 2020). Nevertheless, there are numerous shortcomings. The major challenge is the interfacial compatibility of straw fiber materials and virgin/recycled adhesives with other components in bio-composite board system (Mohanty et al. 2018).

Research has focused on self-insulating concrete composite blocks with rice straw insulation blocks as the filler. These composite blocks present the advantage of making up for the insufficient heat storage capacity and thermal inertia index of hollow concrete blocks, which then improves the indoor thermal and humid environment. The composite blocks also have a strong bearing capacity and can avoid mildew and rot of rice straw insulation blocks under high humidity. However, rice straw insulation blocks as the fillers of self-insulating composite blocks do have some problems regarding their preparation. These issues were outlined in research by Lu et al. (2010). First, the pretreatment time of the rice straw can be too long to make it feasible for industrial production. Second, the rice straw fibers can swell by absorbing water when they are soaked in the alkaline solution. Pressing the straw insulation block by the external force can cause a lot of alkaline liquid waste, which can pollute the environment. Finally, by relying on the self-bonding properties of the rice straw and the external force of the pressing to achieve the bonding and molding of the rice straw insulation blocks, the shape of the finished product was warped.

The pretreatment of rice straw can break the tight structure between cellulose, hemicellulose, and lignin so that the rice straw can bond better. Research has revealed that the physical crushing of biomass material could effectively disrupt and modify the biomass structure to increase the surface area of the biomass material (Zheng et al. 2015). The increasing surface could be more beneficial to the reaction between the rice straw and the alkaline solution. Thus, physical damage such as mechanical stirring combined with lye soaking could significantly improve the pretreatment efficiency of rice straw.

Lime as binding material for decorative plasters or masonry mortar has been used as a construction material for thousands of years in China (Dai 2013). When lime is slaked, it reacts with water and precipitates calcium hydroxide crystals. In a dry environment, 
calcium hydroxide reacts with carbon dioxide in the air to form calcium carbonate, which is called carbonization. The chemical reaction formula is as Eq. 1 (Zilch et al. 2014):

$$
\mathrm{Ca}(\mathrm{OH})_{2}+\mathrm{CO}_{2}+\mathrm{nH}_{2} \mathrm{O}=\mathrm{CaCO}_{3} \downarrow+(n+1) \mathrm{H}_{2} \mathrm{O}+\mathrm{Q}
$$

The generated calcium carbonate and calcium hydroxide work synergistically in the lime slurry. It can be seen from the chemical formula that carbon dioxide is required for the reaction, and carbonization occurs mainly on the surface in contact with air. A calcium carbonate film that is hard and has a certain strength is formed on the surface of the lime slurry. It covers the surface of the structure to wrap and bond the material. That is to say, lime can be used as a cementitious material. Liu (2010) studied the influence of various gelling media on the shaping of wheat stalks and finally chose slaked lime slurry. He determined that after $26 \mathrm{~d}$ of curing, the quality of the wheat stalks remained unchanged, indicating that the hardening of lime slurry and evaporation of water reach stability. Though the slaked lime does not harden absolutely in tens of days, it still has several desirable properties, such as good adhesion, antimicrobial capability, and aesthetic appearance (Shirakawa et al. 2003; Alphin et al. 2009). In addition, the slaked lime gradually changes to calcium carbonate, which has higher mechanical strength with time (Toniolo et al. 2011).

Expanded polystyrene (EPS) foam has many excellent characteristics: a low density, good shock absorption, good thermal and sound insulation performance, a high specific strength, waterproof characteristics, and acid and alkali resistance. Waste polystyrene foam is also hard to degrade naturally. If they are recycled, that can avoid plastic pollution. Sayil and Gürdal (1999) investigated gypsum blocks that contained polystyrene foam beads. The results indicated that the polystyrene foam beads could reduce the thermal conductivity and density of such composites.

Therefore, this study used mechanical stirring as a pretreatment method and added hydrated lime powder as a gelatinizing agent to research rice straw resources integrated with EPS particle waste as building materials, based on previous research. The study aimed to pave the way for the industrial production of the rice straw insulation blocks and provide a new idea and reference for the utilization of crop straw and plastic waste as building materials through studies of the material matching ratio and the properties of rice straw insulation blocks.

\section{EXPERIMENTAL}

\section{Preparation Process of Rice Straw Insulation Block}

The rice straw (XiDaYou216) was obtained from an experimental farm of Southwest University in Chongqing, in southwest China. The rice straw was trimmed into small pieces ( 3 to $4 \mathrm{~cm}$ ) with a grass cutter (Xianglong Hardware Machinery, Shandong, China), dried in an electric heating constant temperature drying oven (DHG-9240A; Shanghai Qixin Scientific Instruments Co., Shanghai, China) at $60{ }^{\circ} \mathrm{C}$ to a constant weight (about $36 \mathrm{~h}$ ), and then kept in sealed plastic bags. Sodium hydroxide $(\mathrm{NaOH})$ (Chuandong Chemical Industry Co., Chongqing, China) with a purity greater than $96 \%$ was prepared into a solution with a mass fraction of $1 \%$, which was determined by previous research (Sun et al. 2020). The rice straw was soaked in the $\mathrm{NaOH}$ solution for $3 \mathrm{~h}$. The soaked rice straw was stirred directly using a cement mortar mixer at a high speed for $5 \mathrm{~min}$. The soaking time and the stirring time were only changed if specified. The purpose of this step 
was to use mechanical force to destroy the structure of the rice straw and shorten the soaking time. The slaked lime or the EPS particles were stirred together with the rice straw when they needed to be added. At this point, the pretreatment was complete.

The rice straw or pretreated mixture was poured into the mold $(70.7 \mathrm{~mm} \times 70.7 \mathrm{~mm}$ $\times 70.7 \mathrm{~mm}$ ) and then compacted into stable form vertically with pressure applied via a microcomputer-controlled electron universal tester (YAD-2000; Changchun Kexing Test Instrument Co., Jilin, China). The mold was removed after $24 \mathrm{~h}$, and the rice straw insulation block was cured for $28 \mathrm{~d}$ (the time required for quality stabilization of rice straw insulation block by tests) at an appropriate atmosphere and temperature.

\section{Methods}

Forming test

Due to the combination of mechanical stirring and the $\mathrm{NaOH}$ solution soaking, the softening method of the straw had changed. Furthermore, to be more conducive to the bonding between the rice straw and the forming of the rice straw insulation blocks, new composition materials were added, namely slaked lime and EPS particles. The tests to explore the impact of these changes on the forming of the rice straw insulation blocks were designed as follows.

The first was the effect of the mechanical stirring and slaked lime on the rice straw insulation blocks. The material consumption and test conditions are outlined in Table 1. To reveal the forming principle of the rice straw insulation blocks, the cross-section of Sample D (control) was scanned by a scanning electron microscope (SEM) (Phenom-World, Eindhoven, Netherlands). Next, the dosage of the EPS particles' ( $\omega$ EPS) influence on the rice straw insulation blocks was examined. The $\omega$ EPS value was the mass percentage of EPS particles to rice straw. Samples F to J were set, and the $\omega$ EPs values for samples F, G, H, I, and $\mathrm{J}$ were $2 \%, 4 \%, 6 \%, 7 \%$, and $8 \%$, respectively. The mass ratio of the slaked lime to rice straw (RSR) was $1 / 6$, and the other conditions remained unchanged.

Table 1. Material Consumption and Test Conditions

\begin{tabular}{|c|c|c|c|c|c|c|}
\hline Sample & $\begin{array}{c}\text { Mass Fraction of } \\
\text { NaOH Solution } \\
(\mathbf{\%})\end{array}$ & $\begin{array}{c}\text { Rice } \\
\text { Straw (g) }\end{array}$ & $\begin{array}{c}\text { Slaked } \\
\text { Lime (g) }\end{array}$ & RSR $^{*}$ & $\begin{array}{c}\text { Soaking } \\
\text { Time (h) }\end{array}$ & $\begin{array}{c}\text { Stirring } \\
\text { Time (min) }\end{array}$ \\
\hline A & 1 & 100 & 16.7 & $1 / 6$ & 6 & 0 \\
\hline B & 1 & 100 & 16.7 & $1 / 6$ & 6 & 5 \\
\hline C & 1 & 100 & 33.3 & $1 / 3$ & 3 & 5 \\
\hline D & 1 & 100 & 16.7 & $1 / 6$ & 3 & 5 \\
\hline E & 1 & 100 & 16.7 & $1 / 6$ & 1 & 5 \\
\hline $\begin{array}{l}\text { * RSR is the mass ratio of slaked lime to rice straw; RSR=1/6 was obtained through the pre- } \\
\text { test. }\end{array}$
\end{tabular}

\section{Orthogonal design}

The thermal performance and the self-weight of the straw insulation blocks had a strong relationship with the dry apparent density. In addition, the RSR, the $\omega$ EPs, and the mechanical stirring time of the rice straw insulation block were all related to the dry apparent density. Therefore, an orthogonal experiment was designed to explore the influence of the three factors on the dry apparent density. The levels of the orthogonal experimental factors are shown in Table 2. 
Table 2. Levels of the Orthogonal Experimental Factors

\begin{tabular}{|c|c|c|c|}
\hline \multirow{2}{*}{ Levels } & \multicolumn{3}{|c|}{ Factors } \\
\cline { 2 - 4 } & RSR & $\boldsymbol{\omega}_{\text {EPS }}$ (\%) & Stirring Time (min) \\
\hline 1 & $1 / 3$ & 2 & 5 \\
\hline 2 & $1 / 6$ & 4 & 10 \\
\hline 3 & $1 / 9$ & 6 & 15 \\
\hline
\end{tabular}

The RSR and WEPS testing

The arrangement of the RSR and $\omega$ EPS tests is shown in Table 3 . The $R$ and $E$ tests for the dry apparent density of the finished rice straw insulation blocks were conducted in accordance with the GB/T standard 6343-2009 (2009). The thermal conductivity of the $R$ was measured with an intelligent flat thermal conductivity tester (DRCD-3030A; Shanghai Meiyu Instrument Equipment Co., Shanghai, China). After the samples were dried to a constant weight, their qualities were measured every day in a laboratory environment, and their moisture content (MC) was calculated to reflect the moisture absorption of the $E$ test. The MC of the sample was calculated according to Eq. 2,

$$
M C(\%)=\left(W_{t}-W_{0}\right) 100 / W_{t}
$$

where $W_{t}$ is the mass of the sample at day $t$ and $W_{0}$ is the initial mass of the dried sample.

Table 3. Arrangement of the Tests of the RSR and the wEPS

\begin{tabular}{|c|c|c|c|c|c|c|c|c|c|}
\hline \multirow{2}{*}{ Test R } & Sample & $\mathrm{R} 1$ & $\mathrm{R} 2$ & $\mathrm{R} 3$ & $\mathrm{R} 4$ & $\mathrm{R} 5$ & $\mathrm{R} 6$ & $\mathrm{R} 7$ & \multirow{2}{*}{$\omega_{\text {EPS }}=3 \%$} \\
\cline { 2 - 11 } & $\mathrm{RSR}$ & 0 & $1 / 10.5$ & $1 / 9$ & $1 / 7.5$ & $1 / 6$ & $1 / 4.5$ & $1 / 3$ & \\
\hline \multirow{2}{*}{ Test E } & Sample & $\mathrm{E} 1$ & $\mathrm{E} 2$ & $\mathrm{E} 3$ & $\mathrm{E} 4$ & $\mathrm{E} 5$ & $\mathrm{E} 6$ & $\mathrm{E} 7$ & \multirow{2}{*}{$\mathrm{RSR}=1 / 6$} \\
\cline { 2 - 11 } & $\omega_{\mathrm{EPS}} / \%$ & 0 & 1 & 2 & 3 & 4 & 5 & 6 & \\
\hline
\end{tabular}

\section{RESULTS AND DISCUSSION}

\section{Result of the Forming Test}

The dimensions for evaluating the molding effect of the samples included the shape regularity, the surface flatness, and the material bonding status. The molded rice straw insulation blocks are shown in Fig. 1. Comparing the forming effects of sample A and sample B, the mechanical stirring made the shape of the blocks more regular, the surface of the blocks flatter, and the materials of the blocks more firmly bonded. Sample B was judged to be better than sample $D$, and sample $D$ was better than sample $E$, which proved that a longer soaking time was more conducive to forming. However, the forming effect of sample D was only slightly worse than that of sample B. That is to say, with the mechanical stirring, appropriately reducing the soaking time did not affect the forming effect. Therefore, the soaking time was cut from $6 \mathrm{~h}$ to $3 \mathrm{~h}$.

Sample C was flat and tightly bonding because of the more slaked lime content, which showed that the slaked lime helped the blocks to bond and form. As shown in Fig. 2 , the calcium carbonate solids generated by the lime slurry reacting with carbon dioxide were scattered randomly on various parts of the rice straw. The calcium carbonate solids wrapped on the surface of the rice straw and filled the voids, making the composite material into a relatively solid whole. 
a)

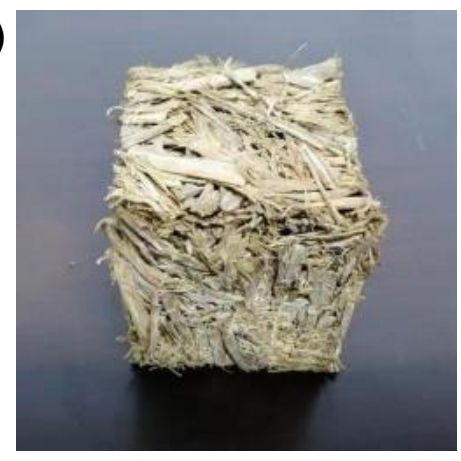

b)

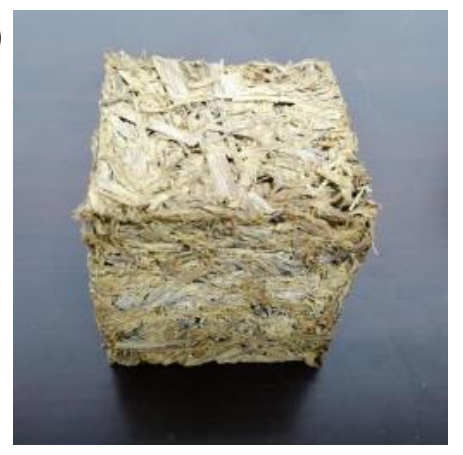

c)

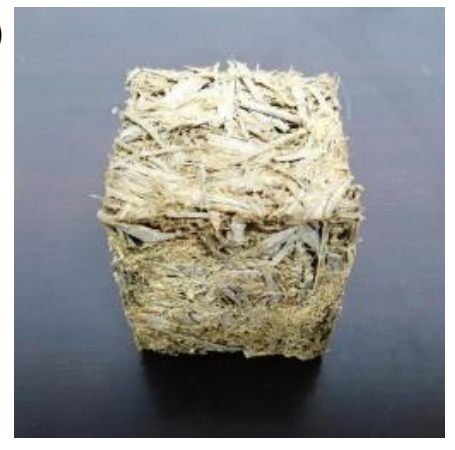

d)

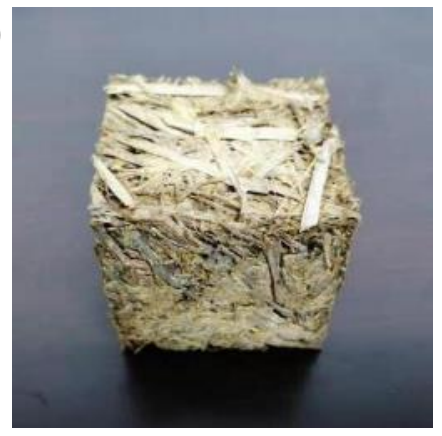

e)

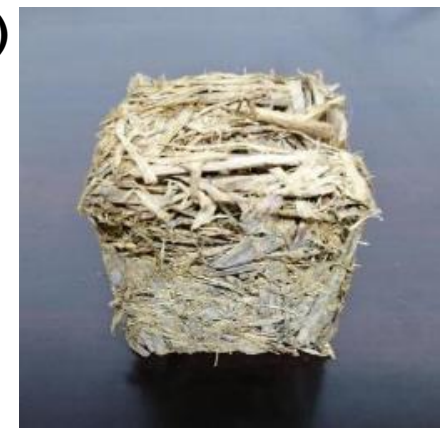

Fig. 1. The forming effect of the rice straw blocks. Images a) through e) correspond to samples A through $\mathrm{E}$, respectively.

a)

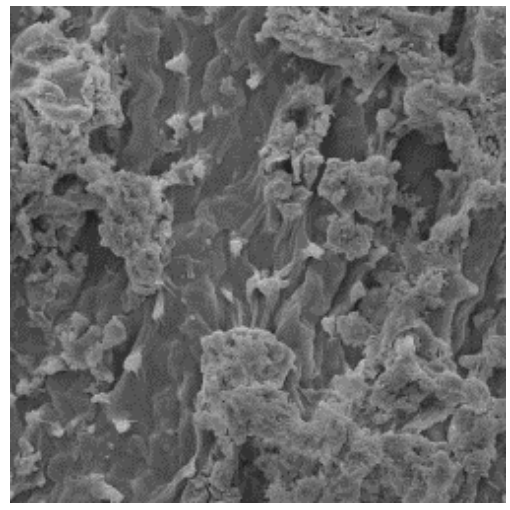

b)

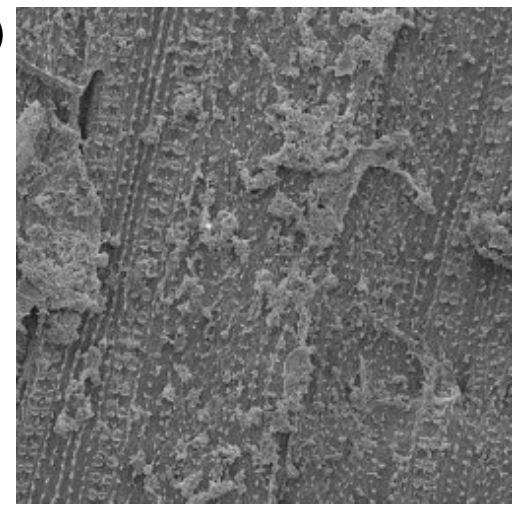

c)

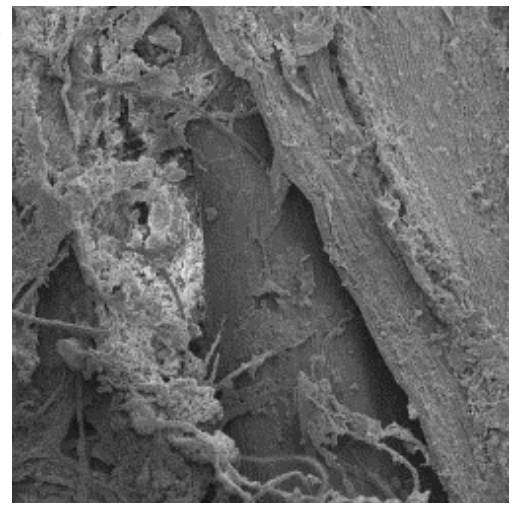

Fig. 2. The apparent morphology analysis of the rice straw insulation block sample by SEM analysis. The sample was magnified at a) 5,000x, b) 1,000x, or c) $500 x$.

The EPS particles affected the bonding of the rice straw and slaked lime, so it was necessary to study the influence of the $\omega$ EPS on the forming of the blocks. The result is shown in Fig. 3. The forming effects of samples F, G, H, and the control sample (sample D) were satisfactory, and there was no significant difference between them. The forming effect of sample I was worse than sample H, and Sample $\mathbf{J}$ had the worst formation. When the $\omega_{\text {EPS }}$ did not exceed $6 \%$, the EPS had little influence on the forming effect of the samples. When the $\omega$ EPs exceeded $6 \%$, the forming of the specimens worsened, presenting a rougher, uneven surface with an irregular shape. The bonding of the rice straw and the lime slurry was seriously hindered by an excess of EPS particles scattered in the material, resulting in poor workability of the mixture. Therefore, to ensure the molding effect of the rice straw insulation blocks, the $\omega$ EPS should not exceed $6 \%$. 


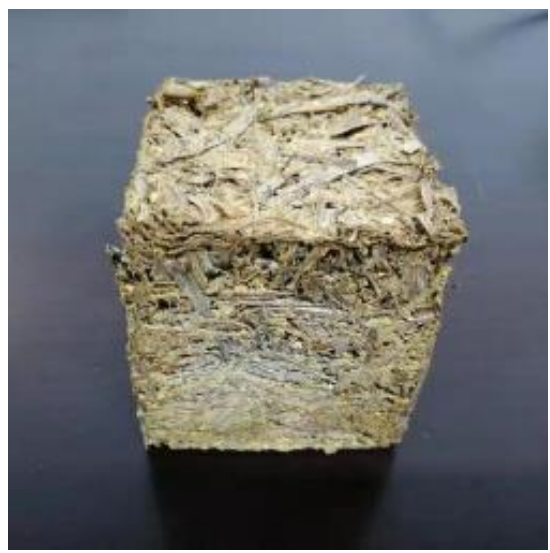

(a)

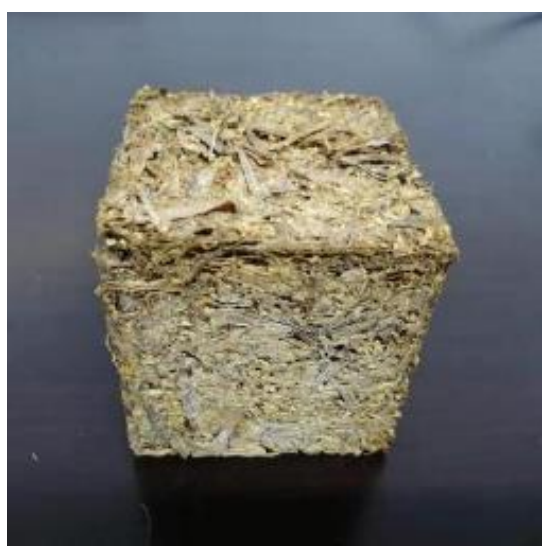

(b)

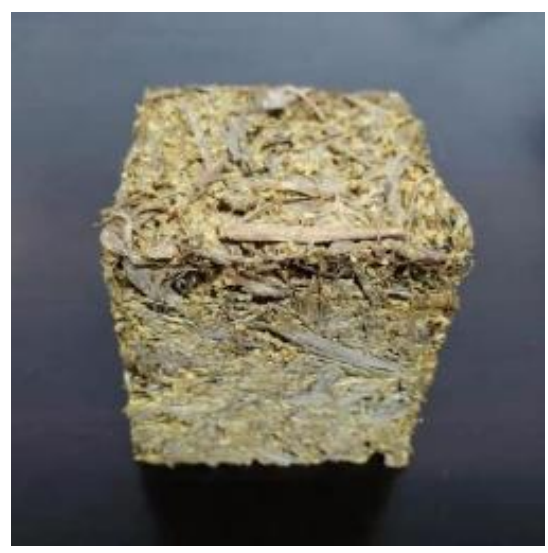

(c)

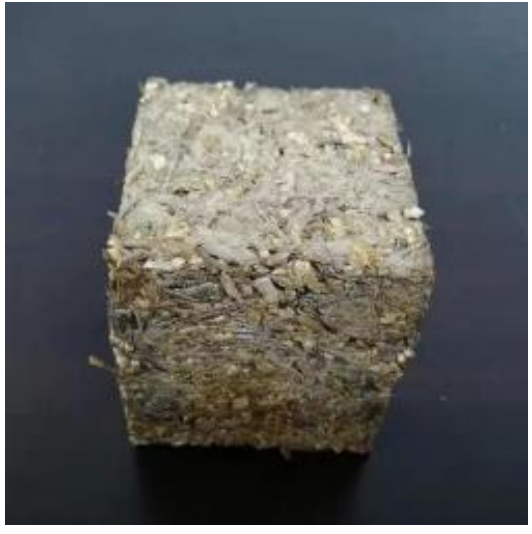

(d)

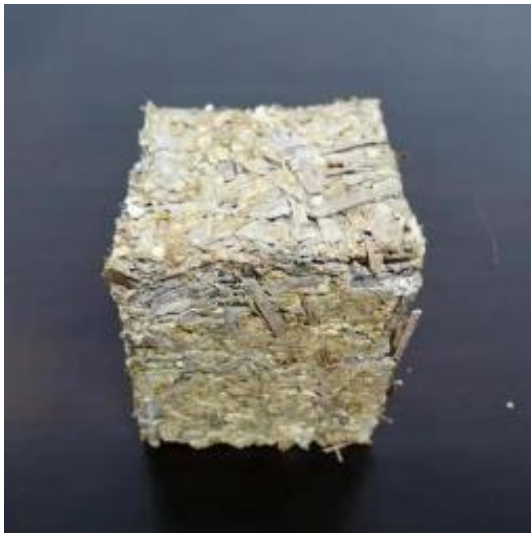

(e)

Fig. 3. The influence of the $\omega_{\text {EPS }}$ on the forming effect of the rice straw block. Images a) through e) correspond to samples $F$ through $J$, respectively.

\section{Analyses of the Dry Apparent Density}

\section{Evaluation of the RSR, WEPS, and stirring time}

The orthogonal design plan and the analysis are shown in Table 4. According to the analysis of variance (ANOVA), the optimal combination was an RSR of $1 / 9$, a $\omega$ EPS of $6 \%$, and a stirring time of $15 \mathrm{~min}$. The F-values of the RSR and the $\omega$ EPS were greater than $\mathrm{F}_{0.01}(2,2)$, which showed that the influences of the RSR and the $\omega_{\mathrm{EPS}}$ on the dry apparent density were particularly significant, and the effect of the RSR was greater than that of the $\omega_{\text {EPS. }}$ However, the F-value of the stirring time was far less than $\mathrm{F}_{0.05}(2,2)$, which indicated that the stirring time had a minimal effect on the dry apparent density. To reduce the costs, the stirring time was set to 5 min during the preparation.

\section{Influence of the RSR on the dry apparent density}

Figure 4 illustrates the influence of the RSR on the dry apparent density. It can be seen that the dry apparent density of the rice straw insulation block gradually decreased as the RSR decreased. Decreasing the RSR meant decreasing the relative content of the slaked lime, which decreased the calcium carbonate solids that were generated during the curing process of the rice straw insulation block. The rice straw was also lighter than the calcium carbonate solids so that the dry apparent density of the rice straw insulation blocks decreased as the calcium carbonate solids content decreased. 
Table 4. Orthogonal Design Plan and Result Analysis

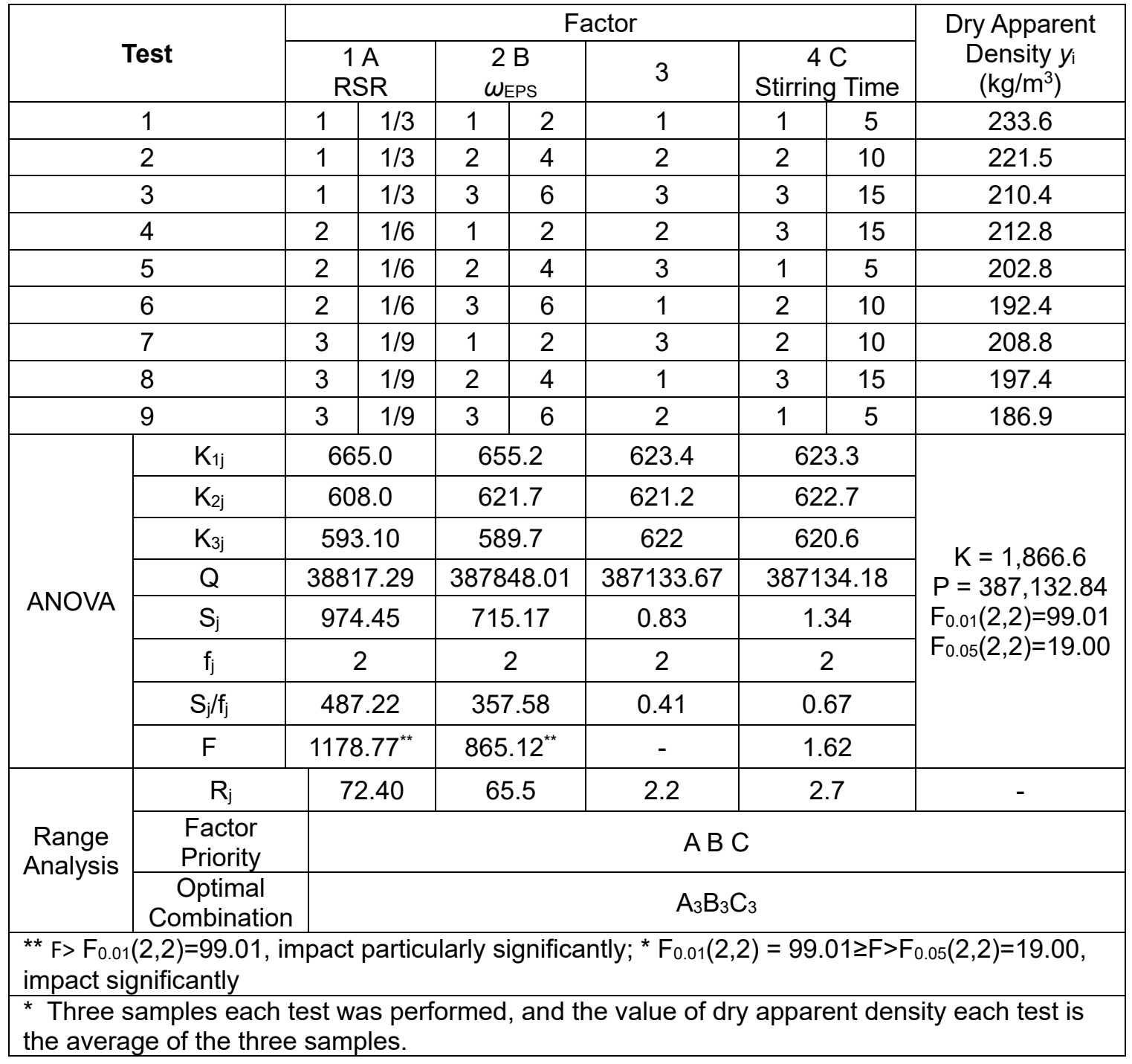

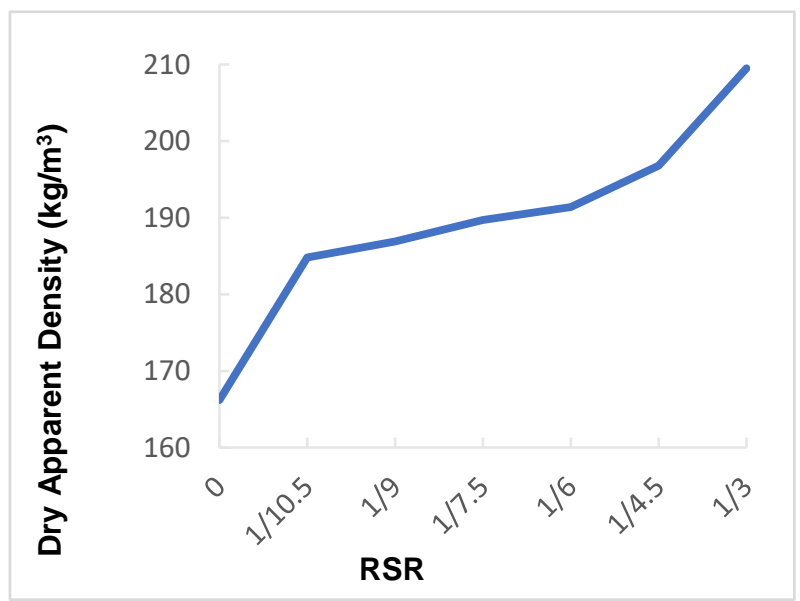

Fig. 4. The influence of the RSR on the dry apparent density 


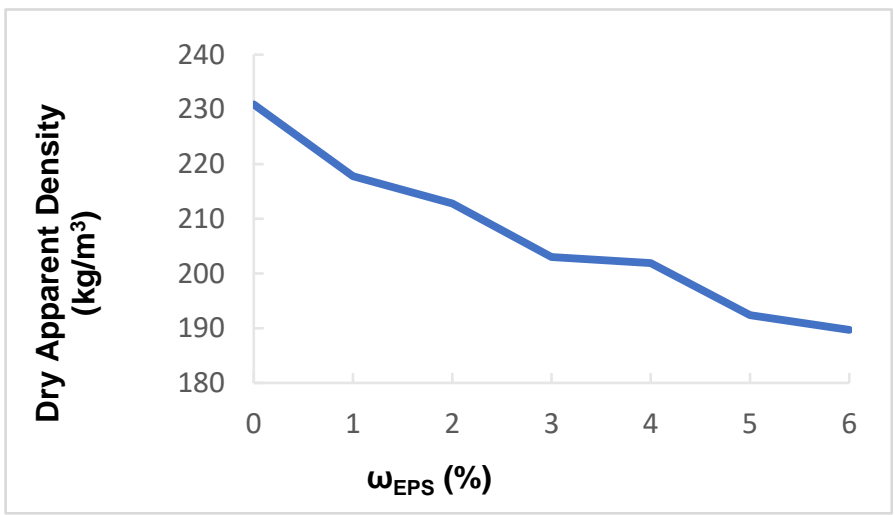

Fig. 5. The influence of the $\omega$ EPS on the dry apparent density

\section{Influence of the $\omega_{E P S}$ on dry apparent density}

The effect of the $\omega$ EPS on the dry apparent density of the rice straw insulation blocks is shown in Fig. 5. It was clear that the dry apparent density of each sample was lower than that of the control, and the dry apparent density of the rice straw insulation blocks gradually decreased as the $\omega$ EPS value increased, showing an obvious linear negative correlation. This was attributed to the extremely low apparent density of the EPS $\left(18\right.$ to $\left.25 \mathrm{~kg} / \mathrm{m}^{3}\right)$. As the $\omega_{\text {EPS }}$ increased, the EPS particles per unit volume of the rice straw insulation blocks increased, causing the dry apparent density of the rice straw insulation blocks to decrease. This result was similar to the conclusions of other scholars and researchers who changed the foam amount to adjust the dry apparent density of foamed concrete (He et al. 2019; Hashim and Tantray 2021; Saheed et al. 2021).

To summarize, the slaked lime increased the density of the rice straw block, but the density was reduced as the $\omega_{\text {EPS }}$ value increased. The coordination of the two factors can ensure that the dry apparent density of the rice straw insulation block meets the criterion that the density of self-insulation filling materials should less than $250 \mathrm{~kg} / \mathrm{m}^{3}$ limit of straw bricks specified in the JG/T standard 407-2013 (2013).

\section{Assessment of the Thermal Conductivity}

The rice straw insulation block, which mainly provided thermal insulation, was the filling material of the self-insulating concrete composite block. The thermal performance of the rice straw insulation block directly determined the thermal performance of the selfinsulating concrete composite block. The thermal conductivity of the rice straw insulation block was an important index to measure the thermal performance, and smaller thermal conductivity and better thermal performance were achieved. Figure 6 demonstrates that each rice straw insulation block had a low thermal conductivity at room temperature. Without the addition of the EPS particles, the thermal conductivity of the rice straw insulation block was approximately $0.049 \mathrm{~W} \cdot \mathrm{m}^{-1} \cdot \mathrm{K}^{-1}$, which is slightly greater than that of the samples with the EPS particles. Compared with aerated concrete and clay brick, the rice straw insulation block had a better thermal performance. Liu and Yu (2002) used a test procedure for rice straw similar to the porosity of textile fibers to determine that the porosity of the stem was $61.0 \%$, the porosity of the leaves was $58.2 \%$, and the porosity of the nodes was $49.4 \%$. The result confirmed that the rice straw itself contained many pores, which hindered the heat transfer inside the straw insulation blocks.

As shown in Fig. 6, the thermal conductivities of the rice straw insulation blocks decreased as the $\omega_{\text {EPS }}$ value was increased. The thermal conductivity of the EPS particles 
was minuscule (approximately $0.043 \mathrm{~W} \cdot \mathrm{m}^{-1} \cdot \mathrm{K}^{-1}$ ), which was less than two times the thermal conductivity of air (approximately $0.027 \mathrm{~W} \cdot \mathrm{m}^{-1} \cdot \mathrm{K}^{-1}$ at room temperature). The EPS particles were randomly scattered in the rice straw insulation block, which was equivalent to increasing the porosity of the insulation materials. This action seriously hindered the internal heat transfer. Therefore, the thermal conductivity decreased as the $\omega$ EPS increased. However, when the $\omega$ EPS exceeded $3 \%$, the rate of change of the thermal conductivity decreased. In this case, the excessive EPS particles affected the cementing effect between the components, which caused air convection by forming several continuous pores extending across the insides of the samples.

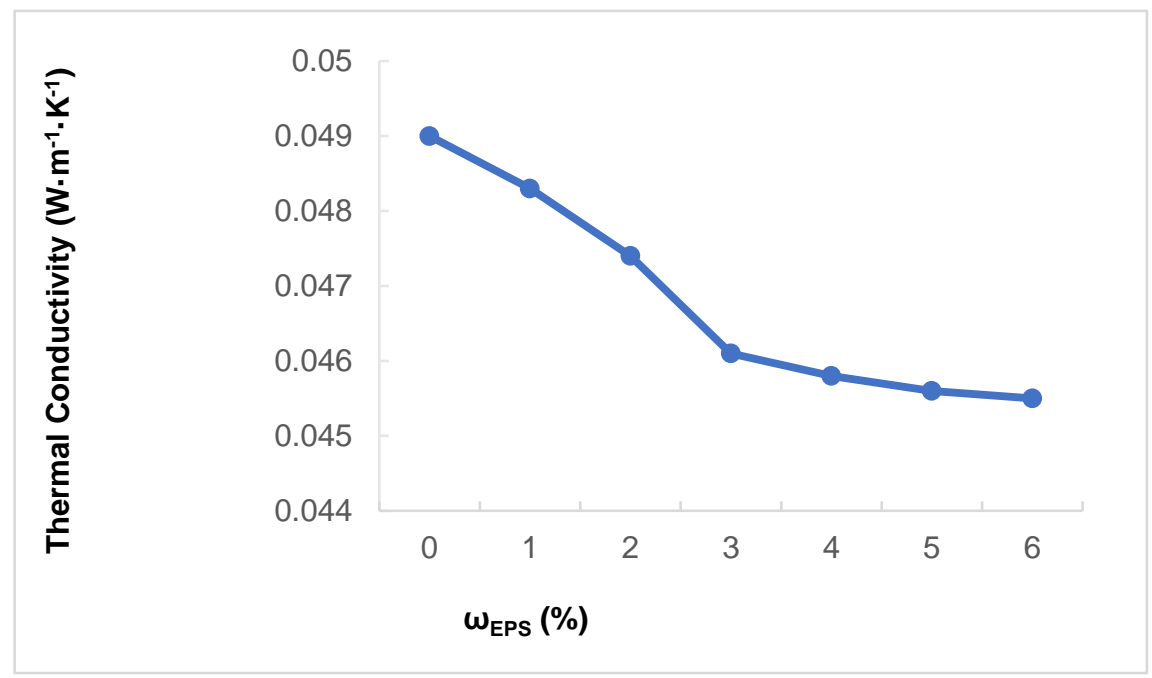

Fig. 6. Effect of the wEPS on the thermal conductivity of the rice straw insulation block

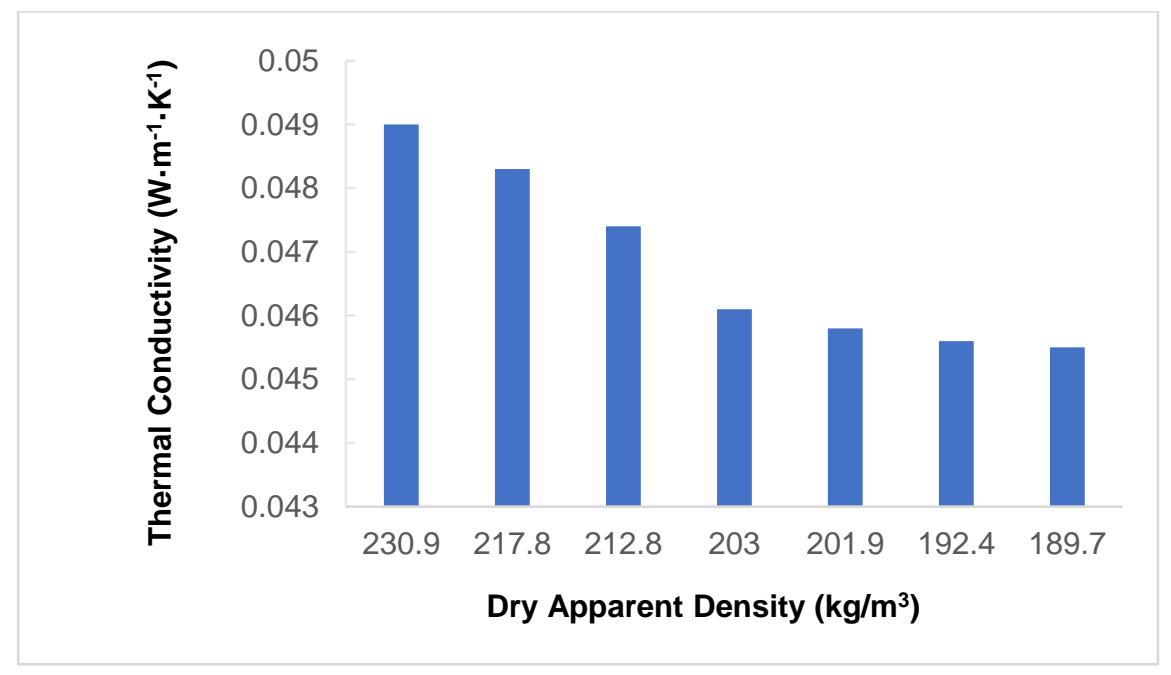

Fig. 7. The relationship between the thermal conductivity and the dry apparent density

According to Fig. 7, the thermal conductivity of the rice straw insulation block decreased as the dry apparent density decreased. This was consistent with the findings of Huang et al. (2011), who found that the increment or decrement of the straw wall's thermal conductivity was maintained with its density. 


\section{Assessment of the Moisture Absorption}

The moisture absorption of the rice straw insulation blocks is a key factor in determining their durability and mildew resistance. Figure 8 displays the hygroscopic process of each sample. The temperature in the laboratory ranged from 13 to $19{ }^{\circ} \mathrm{C}$, and the relative humidity range was $70 \%$ to $82 \%$. Over time, the $\mathrm{MC}$ of the rice straw insulation blocks gradually increased. On the first day, the MC increased significantly because the rice straw insulation blocks had been dried to a constant weight and atmospheric pressure forced water into the samples. Within 2 to 6 days, the MC of the rice straw insulation blocks continued to rise. After the sixth day, the MC of the rice straw insulation blocks increased slowly. On the seventh day, the MC of the rice straw insulation blocks dropped slightly, which was caused by the decrease in the relative humidity of the air that day. After the twelfth day, the moisture absorption curve of the rice straw insulation blocks tended to be flat, basically reaching a state of equilibrium.

The equilibrium MC of each rice straw insulation block was relatively high (Table 5), and it exceeded the 17\% MC limit of straw bricks specified in the GB/T standard 508242013 (2013). This can be attributed to three main reasons. First, the rice straw had cellulose, hemicellulose, and other substances that were water-absorbing easily (Lanthong et al. 2006). Second, the water produced during the hardening process of the lime slurry accumulated inside the rice straw insulation block and was hard to volatilize. Third, it was closely related to the relative humidity of the environment, and research has indicated that a higher relative humidity can result in a higher moisture content of straw (Lin et al. 2016). From Table 5, the equilibrium MC of the R7 sample was the lowest, at $18.7 \%$. The equilibrium MC of the R2 and R5 samples were higher, and the difference between the two was only $0.1 \%$. When the RSR was $1 / 7.5$, the equilibrium MC of $19.3 \%$ was at a relatively low level.

For the current situation of the high equilibrium MC of the rice straw insulation block, there are two potential solutions. An RSR value of $1 / 7.5$ or $1 / 3$ is preferable and the rice straw insulation block should not be exposed to an environment of high humidity.

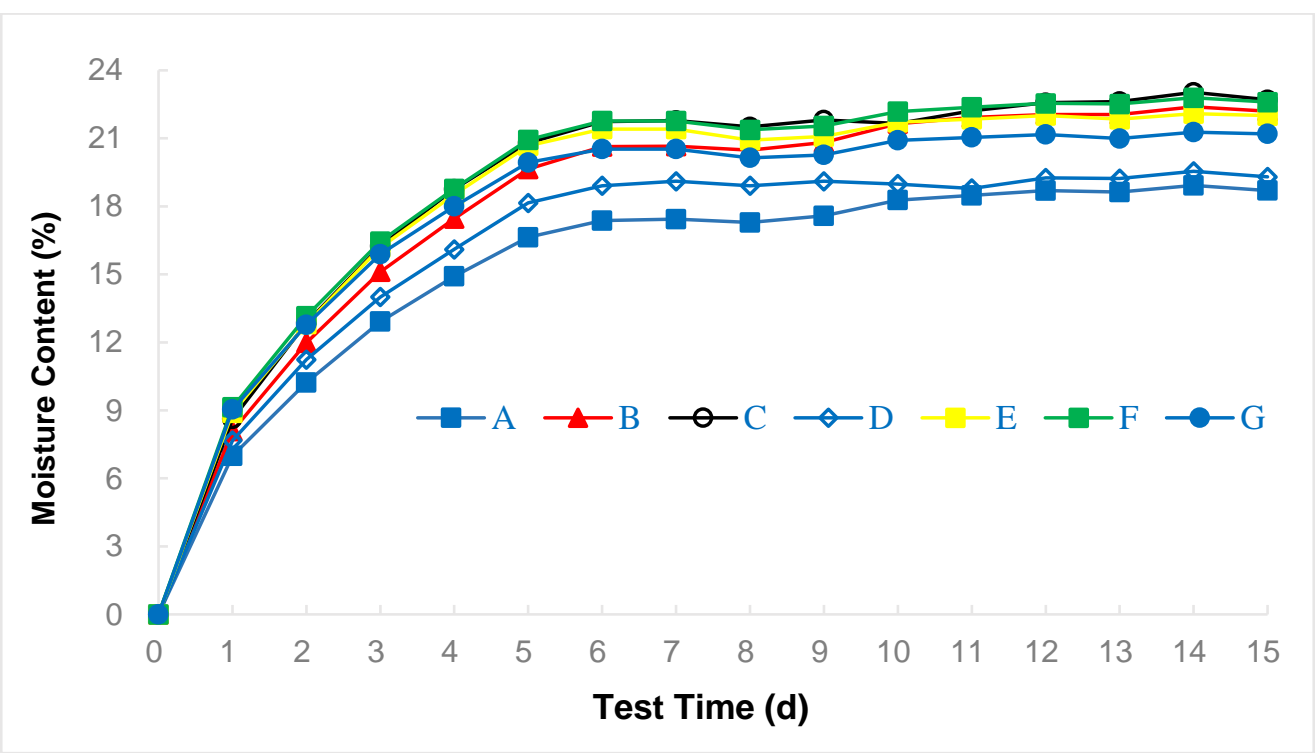

Fig. 8. The hygroscopic process 
Table 5. The Equilibrium MC

\begin{tabular}{|c|c|c|c|c|c|c|c|}
\hline Test $\mathbf{R}$ & $\mathbf{R 1}$ & $\mathbf{R 2}$ & $\mathbf{R 3}$ & $\mathbf{R 4}$ & $\mathbf{R 5}$ & $\mathbf{R 6}$ & $\mathbf{R 7}$ \\
\hline RSR & 0 & $1 / 10.5$ & $1 / 9$ & $1 / 7.5$ & $1 / 6$ & $1 / 4.5$ & $1 / 3$ \\
\hline Equilibrium MC (\%) & 20.9 & 22.6 & 22.0 & 19.3 & 22.7 & 22.2 & 18.7 \\
\hline
\end{tabular}

\section{CONCLUSIONS}

1. The pretreatment method of lye soaking combined with mechanical stirring was found to effectively soften the rice straw to make it thinner and softer, thereby shortening the needed soaking time from 6 to $3 \mathrm{~h}$. The slaked lime and expanded polystyrene (EPS) particles worked together to promote the better bonding and molding of the rice straw insulation block while maintaining a small self-weight.

2. The dry apparent density of the rice straw insulation block increased with the augment of the ratio of slaked lime to rice stray (RSR), which indicated that the dry apparent density increased as the slaked lime dosage increased. The relationship of the water content in the equilibrium state showed resembled a "wave." It also gradually decreased as the $\omega$ EPS value increased, which illustrated a linear negative correlation. The EPS particles can effectively make up for the deficiency caused by the augment of the slaked lime and control the rice straw insulation block at a relatively low weight per unit volume.

3. The thermal conductivity of rice straw insulation block without the EPS particles was approximately $0.049 \mathrm{~W} \cdot \mathrm{m}^{-1} \cdot \mathrm{K}^{-1}$, which was less than the $0.08 \mathrm{~W} \cdot \mathrm{m}^{-1} \cdot \mathrm{K}^{-1}$ specified in the JG/T standard 407-2013 (2013). When the EPS particles content increased, the $\omega$ EPS increased. This decreased the thermal conductivity of the straw brick so that the thermal insulation performance was improved. However, when the $\omega_{\text {EPS }}$ was more than $3 \%$, there was no apparent improvement in the thermal insulation performance. Therefore, the $\omega$ EPS should be controlled within $3 \%$.

4. The rapid pretreatment technology was determined to require lye soaking for $3 \mathrm{~h}$ and mechanical stirring for $5 \mathrm{~min}$. The material matching ratio scheme was determined to require a $\omega$ EPS value less than or equal to $3 \%$ and an RSR value equal to $1 / 7.5$.

\section{ACKNOWLEDGMENTS}

This work was funded by the Chongqing Technology Innovation and Application Development Project (cstc2019jscx-gksbX0118). 


\section{REFERENCES CITED}

Aladejana, J. T., Wu, Z., Fan, M., and Xie, Y. (2020). "Key advances in development of straw fibre bio-composite boards: An overview," Materials Research Express 7(1), 012005. DOI: 10.1088/2053-1591/ab66ec

Alphin, R. L., Johnson, K. J., Ladman, B. S., and Benson, E. R. (2009). "Inactivation of avian influenza virus using four common chemicals and one detergent," Poultry Science 88(6), 1181-1185. DOI: 10.3382/ps.2008-00527

Bhattacharyya, P., Bhaduri, D., Adak, T., Munda, S., Satapathy, B. S., Dash, P. K., Padhy, S. R., Pattanayak, A., Routray, S., Chakraborti, M., et al. (2020).

"Characterization of rice straw from major cultivars for best alternative industrial uses to cutoff the menace of straw burning," Industrial Crops and Products 143, article no. 111919. DOI: 10.1016/j.indcrop.2019.111919

Carlini, M., Allegrini, E., Zilli, D., and Castellucci, S. (2014). "Simulating heat transfers through the building envelope: A useful tool in the economical assessment," Energy Procedia 45, 395-404. DOI: 10.1016/j.egypro.2014.01.043

Dai, S. (2013). "Building limes for cultural heritage conservation in China," Heritage Science 1(1), 1-9. DOI: 10.1186/2050-7445-1-25

Florea, I., and Manea, D. L. (2019). "Analysis of thermal insulation building materials based on natural fibers," Procedia Manufacturing 32, 230-235. DOI:

10.1016/j.promfg.2019.02.207

GB/T 50824-2013 (2013). "Design standard for energy efficiency of rural residential buildings," Standardization Administration of China, Beijing, China.

GB/T 6343-2009. (2009). "Cellular plastics and rubbers," Standardization Administration of China, Beijing, China.

Hashim, M., and Tantray, M. (2021). "Comparative study on the performance of protein and synthetic-based foaming agents used in foamed concrete," Case Studies in Construction Materials 14, article no. e00524. DOI: 10.1016/J.CSCM.2021.E00524

He, J., Gao, Q., Song, X., Bu, X., and He, J. (2019). "Effect of foaming agent on physical and mechanical properties of alkali-activated slag foamed concrete," Construction and Building Materials 226, 280-287. DOI: 10.1016/j.conbuildmat.2019.07.302

Huang, B., Xu, Q., Chu, W., and Zhou, D. (2011). "Research on thermal insulation performance of straw lightweight wall," Forest Industry 4, 20-22. DOI: 10.19531/j.issn1001-5299.2011.04.006

Huo, T., Ren, H., Zhang, X., Cai, W., Feng, W., Zhou, N., and Wang, X. (2018). "China's energy consumption in the building sector: A statistical yearbook-energy balance sheet based splitting method," Journal of Cleaner Production 185, 665-671. DOI: 10.1016/j.jclepro.2018.02.283

Hussein, Z., Ashour, T., Khalil, M., Bahnasawy, A., Ali, S., Hollands, J., and Korjenic, A. (2019). "Rice straw and flax fiber particleboards as a product of agricultural waste: An evaluation of technical properties," Applied Sciences 9(18), article no. 3878. DOI: $10.3390 /$ app9183878

JG/T 407-2013. (2013). "Self-insulation concrete compound blocks," Chinese National Committee for Standardization, Beijing, China.

Koh, C. H. and Kraniotis, D. (2020). "A review of material properties and performance of straw bale as building material," Construction and Building Materials 259, 120385.

DOI: 10.1016/J.CONBUILDMAT.2020.120385 
Lanthong, P., Nuisin, R., and Kiatkamjornwong, S. (2006). "Graft copolymerization, characterization, and degradation of cassava starch- $g$-acrylamide/itaconic acid superabsorbents," Carbohydrate Polymers 66(2), 229-245. DOI:

10.1016/j.carbpol.2006.03.006

Lin, G., Yang, H., Wang, X., Mei, Y., Li, P., Shao, J., and Chen, H. (2016). "The moisture sorption characteristics and modelling of agricultural biomass," Biosystems Engineering 150, 191-200. DOI: 10.1016/j.biosystemseng.2016.08.006

Liu, H., and Yu, Z. (2002). "Properties of straw fiber," Journal of Donghua University (Natural Science Edition) 2,123-128. DOI: 10.3969/j.issn.1671-0444.2002.02.027

Liu, Y. (2010). "Research and development of fiber concrete sandwich straw compression block wall," Shandong Agricultural University.

Lu, Z., Liu, F., Zhang, Y., and Ma, F. (2010). "Effect of wheat straw content on deformation of lime insulation block," The Forestry Science and Technology 35(1), 32-34. DOI: 10.3969/j.issn.1001-9499.2010.01.011

Marques, B., Tadeu, A., Almeida, J., António, J., and de Brito, J. (2020). "Characterisation of sustainable building walls made from rice straw bales," Journal of Building Engineering 28, 101041. DOI: 10.1016/j.jobe.2019.101041

Mohanty, A. R., Vivekanandhan, S., Pin, J.-M., and Misra, M. (2018). "Composites from renewable and sustainable resources: Challenges and innovations," Science 362(6414), 536-542. DOI: 10.1126/science.aat9072

Mutani, G., Azzolino, C., Macrì, M., and Mancuso, S. (2020). "Straw buildings: A good compromise between environmental sustainability and energy-economic savings," Applied Sciences 10(8), 2858. DOI: 10.3390/app10082858

Saheed, S., Amran, Y. H. M., El-Zeadani, M., Aziz, F. N. A., Fediuk, R., Alyousef, R., and Alabdulijabbaer, H. (2021). "Structural behavior of out-of-plane loaded precast lightweight EPS-foam concrete C-shaped slabs," Journal of Building Engineering 33, 101597. DOI: 10.1016/J.JOBE.2020.101597

Saini, J. K., Saini, R., and Tewari, L. (2015). "Lignocellulosic agriculture wastes as biomass feedstocks for second-generation bioethanol production: Concepts and recent developments," 3 Biotech 5, 337-353 (2015). DOI: 10.1007/s13205-014-0246-5

Sayil, B., and Gürdal, E. (1999). "The physical properties of polystyrene aggregated gypsum blocks," in: $8^{\text {th }}$ International Conference on Durability of Building Materials and Components, Vancouver, Canada, pp. 496-504.

Shirakawa, M. A., Beech, I. B., Tapper, R., Cincotto, M. A., and Gambale, W. (2003). "The development of a method to evaluate bioreceptivity of indoor mortar plastering to fungal growth," International Biodeterioration \& Biodegradation 51(2), 83-92. DOI: 10.1016/S0964-8305(01)00129-9

Sun, D., Bao, A., and Chen, L. (2020). "Study on softening effect of $\mathrm{NaOH}$ pretreatment on rice straw," Journal of Southwest China Normal University (Natural Science Edition) 2020(2), 73-78. DOI: 10.13718/j.cnki.xsxb.2020.02.011

Sun, F., and Yu, J. (2021). "Improved energy performance evaluating and ranking approach for office buildings using simple-normalization, entropy-based TOPSIS and K-means method," Energy Reports 7, 1560-1570. DOI: 10.1016/J.EGYR.2021.03.007

Toniolo, L., Paradisi, A., Goidanich, S., and Pennati, G. (2011). "Mechanical behaviour of lime based mortars after surface consolidation," Construction and Building Materials 25(4), 1553-1559. DOI: 10.1016/j.conbuildmat.2010.08.010 
Zheng, J., Choo, K., and Rehmann, L. (2015). "The effects of screw elements on enzymatic digestibility of corncobs after pretreatment in a twin-screw extruder," Biomass and Bioenergy 74, 224-232. DOI: 10.1016/j.biombioe.2015.01.022

Zilch, K., Diederichs, C. J., Katzenbach, R., and Beckmann, K. J. (eds.). (2014). Grundlagen des Bauingenieurwesens, Vol. 1, Springer-Verlag.

Article submitted: September 10, 2021; Peer review completed: October 23, 2021; Revised version received: November 26, 2021; Accepted: November 29, 2021; Published: December 6, 2021. DOI: 10.15376/biores.17.1.699-713 